\title{
Conflictos socioambientales en el proyecto gasoducto sur peruano provincia de Canas - Cusco
}

\section{Socio-environmental Problems Surrounding the South Peruvian Gas Pipeline Project Province of Canas - Cusco}

Ronny Andree Chacon Guevara ${ }^{1, a}$

0000-0003-2484-8404

Emilio Flores Mamani ${ }^{2, b}$

0000-0002-3673-6613

Delmia Socorro Valencia Blanco ${ }^{1, \mathrm{c}}$

0000-0003-3198-5415

Nilda Quispe Cornejo ${ }^{3, d}$

0000-0001-7765-6276

\footnotetext{
${ }^{1}$ Universidad Nacional de San Antonio Abad del Cusco.

${ }^{2}$ Universidad Nacional del Altiplano.

${ }^{3}$ Dirección Desconcentrad de Cultura de Cusco.

a ronnyandree@hotmail.com

b emilioflores@unap.edu.pe

cdelmia.valencia@unsaac.edu.pe

d nildafernanda@hotmail.com
}

\section{Resumen}

Los enfrentamientos entre las empresas privadas y las poblaciones locales se dan permanentemente en el Perú en los procesos de extracción energética por alteraciones en aspectos socioeconómicos, ambientales y culturales de los pueblos. El objetivo fue analizar los conflictos socioambientales entre la empresa constructora Odebrecht y las Comunidades Campesinas de la Provincia de Canas - Cusco involucradas en el proyecto Mejoras a la Seguridad Energética del País y Desarrollo del Gasoducto Sur Peruano. La población informante fue 320 de 8 Comunidades Campesinas y representantes de la empresa, el diseño es etnográfico y método cualitativo. Los resultados muestran oposición categórica de los pobladores a la construcción del proyecto, debido a la disconformidad con el accionar errado de la empresa en los procesos de diálogo, interrelación y comunicación. Se concluye que los proyectos de impacto ambiental sin una línea de base social, cultural, económica y medio ambiental establecida generan enfrentamientos complejos de solucionar.

Palabras clave: Problemáticas Sociales, conflictos, comunidades campesinas, empresas extractivas, medio ambiente.
Recibido: 08/12/2020

Aceptado: 12/02/2021

Pub7icado: 17/03/2021

\begin{abstract}
Confrontations between private companies and local populations are constantly taking place in Peru in the process of energy extraction due to changes in the socio-economic, environmental and cultural aspects of the peoples. The objective was to analyze the socio-environmental conflicts between the construction company Odebrecht and the Peasant Communities of the Province of Canas - Cusco involved in the project Improvements to the Energy Security of the Country and Development of the South Peruvian Gas Pipeline. The informant population was 320 of 8 peasant communities and representatives of the company, the design is ethnographic and qualitative method. The results show categorical opposition of the residents to the construction of the project, due to the disagreement with the wrong actions of the company in the processes of dialogue, interrelation and communication. It is concluded that environmental impact projects without an established social, cultural, economic and environmental baseline generate complex confrontations to solve.
\end{abstract}

Keyword: Social problems, conflicts, peasant communities, extractive companies, environment. 


\section{Introducción}

La problemática socioambiental es una situación negativa caracterizada por una serie de elementos discrepantes y hostiles que ocasionan daños y alteraciones en un espacio de vida. Es un fenómeno natural propio del proceso de convivencia, ha estado presente acompañando al proceso del desarrollo de las sociedades, desde las épocas más primitivas hasta las actuales, desde las más simples hasta las más complejas. Sin embargo, hace algunas décadas se inició una aproximación científica al estudio del conflicto, especialmente en el área de las ciencias sociales.

El conflicto es el choque intencional entre dos seres o grupos de la misma especie que exteriorizan los unos hacia los otros una intención hostil en relación a un derecho, y que, para conservar tratan de romper la resistencia del otro usando la violencia (Entelman, 2005). La posibilidad de examinar un conflicto, sea entre grupos sociales o entre países, demanda estar en posición de un concepto que proporcione análisis y demarque el ámbito de estudio (Castro, 2013). Entonces, se concibe por conflicto a toda analogía de oposición entre dos partes con objetivos incompatibles. Estas dos definiciones no solo se complementan, sino también muestran una condición necesaria de barrera y distanciamiento.

La interacción conflictiva como todo proceso posee motivos, causas y consecuencias, donde las partes están en desacuerdo o tienen posiciones encontradas en relación a la distribución y/o control de los materiales escasos o recursos simbólicos. La cultura establece qué recursos son estimados escasos, condena las estrategias que buscan el provecho o control y crea determinadas instituciones para el manejo de conflictos cuando éstos aparezcan (Ross, 1995). Entonces, cultura es entendida como prácticas instituidas y valores habituales en una sociedad en particular, que vive en un lugar perfectamente delimitado. No todas las culturas valoran de igual manera los mismos objetos y entidades, por tanto, cada conflicto hay que entenderlo en su contexto sociocultural determinado en el cual un mínimo de dos partes pugna al mismo tiempo por obtener el mismo conjunto de recursos escasos (Ortiz, 1999). Involucra condiciones mínimas tales como: la escasez, el deterioro o la privación. Desde una perspectiva sociológica el origen de los conflictos reside en la colisión de intereses de los actores sociales que responden a disímiles identidades y contextualidades espacio - temporales, a diferentes dinámicas de relaciones sociales y de poder (Debuyst, 1999). Entonces, son procesos sociales de enfrentamiento caracterizado por intenciones, motivaciones, propósitos y habilidades en relación a un objetivo común (Tanaka, 2007).

En el Perú, los conflictos han crecido en los últimos años de manera más intensa, duradera y con agendas más complejas, han movilizado cada vez a mayor cantidad de personas quienes se perciben afectadas o excluidas por la actividad, el $50 \%$ de los casos reportados por la Defensoría del Pueblo (2005) fueron categorizados como socioambientales, de los cuales alrededor del 80\% involucran el desarrollo de proyectos energéticos. El Perú es un escenario latente de oposiciones donde no se aborda la problemática de manera estratégica con un modelo de gestión sistémico, contingente y dinámico.

En estudios realizados se enmarcan la situación conflictiva en zonas rurales con recursos energéticos y minerales atractivos para las empresas privadas con intencionalidad de inversión, donde la viabilidad es negación por considerar que los proyectos no producen nada positivo, por el contrario, amenazan la seguridad ambiental local y regional (De Echave et al., 2009). El proyecto Tía María - Arequipa, representó un conjunto de razones e intereses que motivaron la protesta por el temor de un sector de la población por la contaminación del agua, afectación de los cultivos, consecuencias socioeconómicas y falta de confianza traducida en sobornos a los dirigentes que generó la ruptura de dialogo y rechazo del proyecto (Basombrío et al., 2016). En la Amazonia Peruana la empresa Shell accionista mayoritaria a la Corona holandesa, ingresó en Camisea con todas las garantías del Estado para la extracción de petróleo, provocando un desequilibrio negativo en sus aspectos culturales, sociales, ecológicos, económicos y sanitarios (Paredes, 1996). En otros países como el conflicto por las plantas de celulosa en el río Uruguay y el conflicto por la recomposición ambiental de la cuenca MatanzaRiachuelos por la disponibilidad, accesibilidad y gestión del agua, dejó percibir dimensiones clave que ponen en evidencia los quiebres institucionales sistémicos en Argentina (Merlinsky, 2017). Estas compañías irrumpen territorios indígenas y 
áreas protegidas, sus propósitos generan graves conflictos ambientales con las comunidades locales (Gavaldá, 2005).

Se debe precisar que los problemas sociales no deben ser visto como algo negativo, por el contrario, puede ser entendido como un medio para lograr cambios sociales y corregir errores, desde una perspectiva de comprensión y acuerdo mutuo entre las partes involucradas desde su dimensión dialéctica y política, reconocido como un hecho normal que está presente en la cotidianidad y la experiencia del hombre y las sociedades. Esto no quiere decir que no se vea las consecuencias, muchas veces graves, deshumanizantes y trágicas que un conflicto puede traer y que se evidencian en dolor, muerte, sufrimiento, destrucción, miedo, etc. Por ello, debe estar claro que, si bien el conflicto es una realidad que no se puede evitar ni desterrar debe funcionar como herramienta de conducción para prevenir y eliminar consecuencias violentas y destructivas.

Los conflictos socioambientales están vinculados a planteamientos sobre el mal uso y explotación de los recursos naturales que malogran los ecosistemas y el espacio cultural que rodea, pero estos se empeoran cuando de por medio existe un beneficio económico por parte de un tercero. Estos pueden conducir a modificaciones, cambios y/o desarticulación en la estructura de las relaciones entre diversos actores al interior de las sociedades (Ortiz, 2004). Por lo tanto, ocasionaría la desestabilización del grupo humano, generando alteraciones dentro del entorno o grupo social. Conviene subrayar que la escasez de recursos, el movimiento a gran escala de poblaciones, las carencias en la estructura política y legal, son las causas que conforman los conflictos socioambientales.

La interacción e interdependencia entre hombre y naturaleza es fundamental, y es esta la ultima un espacio de vida para fines predeterminados y no un medio para lograr dichos fines (Orellana, 1999). Por ende, la existencia de dos o más grupos, con visiones e intereses opuestos, que disputan entre sí el uso, control, acceso o manejo de espacios o recursos naturales ocasiona la inestabilidad. Las actividades extractivas débilmente reguladas y controladas son fuentes de contaminación que se traducen en daños colaterales a terceros, genera sobrecostos en la agricultura por la disminución de la calidad y cantidad de agua. La sociedad percibe, define y evalúa que determinado contexto ambiental amenazante alcanza una respuesta social, públicamente constituida, encaminada a su remediación o neutralización (Lezama, 2004).

La conflictividad socioambiental, vista desde la ecología política, evidencia nuevas luces de análisis basados en: disputas por el acceso, uso, control y propiedad del medioambiente, así como, su construcción social; la disputa del ambiente, considerado espacio de vida y sobrevivencia ecológica, económica y sociocultural; el despliegue de organizaciones, prácticas y formas de expresión heterogéneas; y la configuración de estos como parte de un contexto político, económico y sociocultural, local y global (Paz, 2014). Por consiguiente, los problemas socioambientales resultan de un proceso de construcción social, por el cual determinada realidad empírica se convierte en un objeto de interés público cuando la sociedad desarrolla la comprensión y conciencia de que está enfrentando una amenaza, un peligro o un hecho extraño, por lo que se obliga a implementar estrategias encaminadas a evaluar y responder a esa situación, siendo el centro los problemas relacionados con el ambiente; por un lado, en cómo las cuestiones ambientales son convertidas en problemas, $y$, por otro, en la autoridad y legitimidad social de las diferentes demandas sobre el medio (Aranda, 2004).

En el contexto actual las diferentes empresas transnacionales han puesto su mirada de inversión en zonas que poseen diferentes potenciales energéticos y económicos. Estos espacios receptores al relacionarse crean una suerte de correspondencia desfavorable debido a las consecuencias negativas que ocasiona la introducción de estas empresas. Esta condición es la denominada "desposesión" (Harvey, 2004), enmarcada en la expropiación geográfica, la expropiación económica y una expropiación ecológica. Por lo tanto, las transnacionales no tienen ningún compromiso multiplicador en el bienestar social, ni de arrastrar a los productores locales al beneficio común de las explotaciones que ellas comandan.

Por otro lado, el Estado es el empleador de la violencia y constructor de la legalidad (Seoane, 2012). Es un poder de clase que flexibiliza las leyes para que las distintas designaciones del capital se 
adueñen de los recursos productivos y financieros. En ese sentido, el Estado permite la depredación de los bienes ambientales (tierra, aire, agua) y la proliferación de la degradación ambiental, transformando la naturaleza en mercancía.

Para las Comunidades Campesinas está en juego su experiencia cotidiana, mientras que para las empresas y el Estado se traduce en términos de orden y racionalidad, cuyo objeto es acostumbrar las actividades sociales para que concuerden con un proyecto económico (Fontaine, 2003). Las secuelas son la afectación en la dimensión económica, el tejido productivo, la dimensión política, la dimensión social, privatización de los servicios públicos e incremento de las desigualdades de género y la dimensión cultural.

El objetivo del artículo es analizar conflictos socioambientales dentro de la contradictoria situación del Proyecto "Mejoras a la seguridad energética del País y desarrollo del Gasoducto Sur Peruano" y "las Comunidades Campesinas de Canas - Cusco" durante los años 2016 al 2017.

\section{Metodología}

La investigación ha contado con la participación de las Comunidades Campesinas de los distritos de Túpac Amaru (Pampahuasi, Toccoccori, Ccochapata, y Ccotaña), Yanaoca (Pongoña, K'ascani, Chignayhua y Hanccoyo). Para el recojo de información sociodemográfica se sustentó en la base de datos municipales y proyectos de inversión en cada sector, del mismo modo, el nexo investigativo de la empresa estuvo caracterizada por el aporte mediador que tuvieron los investigadores al interior de ambos espacios (trabajador de la empresa), facilitando un entendimiento antes, durante y después de cada proceso, evidenciando una eficacia del mismo.

La muestra seleccionada estuvo conformada por 320 pobladores determinada de manera intencional bajo el criterio de informantes claves y representativos en su comunidad. En relación a las características de la muestra fueron pobladores mayores de edad: autoridades comunales, líderes comunales, jefes de hogar, comuneros empadronados, relacionistas comunitarios y otros.

El estudio contempló el diseño etnográfico en su tipología realista o mixta, el cual posee un sentido parcialmente positivista; recolectando datos cuantitativos y cualitativos de la problemática (Valderrama, 2019). Dentro de los enfoques investigativos se recurrió al cualitativo mediante el método hipotético deductivo que conlleva a establecer las observaciones y explicaciones de la realidad efectuadas a la luz de una teoría, comprobada y contrastada por medio del recojo de información empírica objetiva. Dicho método fue plasmado para disentir la información teórica y objetiva. En este sentido, las teorías que encaminaron el proceso fueron: conflictos, conflictos socioambientales y la acumulación por desposesión y las categorías de análisis corresponden a: Conflictos socioambientales, Empresa, Estado y Comunidad Campesina.

La unidad de análisis estuvo conformada por los pobladores de las Comunidades Campesinas antes mencionadas.Porotrolado, launidad deobservación fue las diferentes problemáticas socioambientales suscitadas entre las Comunidades Campesinas y el Proyecto Gasoducto Sur Peruano. Contemplando que la unidad de análisis es el objeto de estudio que tiene la característica de ser abstracta y la unidad de observación son los datos o hechos sobre el que se efectúan las preguntas. Se debe indicar también que el proceso de investigación ha tenido una duración de un año y medio, desde el 2016 hasta el mes de Julio del 2017.

La técnica fue observación participante, constatando de forma presencial y vivencial los diferentes eventos conflictivos socioambientales, también la entrevista según su forma fue no - estructurada, que sirvió para obtención de información de ambos objetivos, usando preguntas abiertas, sin orden preestablecido, adquiriendo características dentro del contexto (Pardo de Vélez y Cedeño, 1997). Este es el clásico dialogo entre el entrevistador y el entrevistado donde la persona interrogada goza de toda la libertad para expresar sobre un caso o una pregunta formulada.

En relación a los instrumentos la cámara filmadora se manejó de forma confidencial, debido a la repercusión que podría causar las capturas fotográficas y videos. Teniendo que recurrir a la libreta de campo para registrar con detalle los diferentes aspectos resaltantes. De manera similar, la guía de entrevista fue el instrumento que encamino el trabajo de campo y recojo de información, compuesta por 30 preguntas con los criterios a identificar dentro de las perspectivas de indagación (Pinilla 2008). 


\section{Resultados y discusión}

\section{Perspectivas de las Comunidades Campesinas de Canas respecto al Proyecto Gasoducto Sur Peruano.}

\section{Inicios del proyecto}

La Provincia de Canas - Cusco está considerada dentro del proyecto Gasoducto Sur Peruano como una de las zonas de influencia directa, dentro de su territorio hubo una serie de modificaciones respecto al lugar por donde iba a pasar la línea de construcción de los ductos. En el año 2013, inició el proyecto bajo la responsabilidad de Kuntur (Transportadora de gas), el recorrido era por otro sector comprometiendo a los territorios de: Pampamarca, Yanaoca, Layme y Llallapara, todas las Comunidades en mención pertenecientes a la provincia de Canas ubicadas a la margen derecha del rio Vilcanota. La empresa tuvo un corto periodo de participación efectuando tareas informativas superficiales. Sin embargo, en su afán de conseguir licencia social aprobaban y obsequiaban peticiones que hacían los pobladores.

En el año 2014 la empresa Odebrecht y Enagas ganaron la licitación pública para la construcción, operación y mantenimiento del proyecto, ambas integrantes del Consorcio Constructor Ductos del Sur. Para la ejecución de los trabajos se desarrollaron una serie de análisis y estudios de impacto ambiental- EIA, que concluyó modificar la traza (matriz de tubería) inicial del proyecto, cambiando su ubicación por otros sectores, a causa del impacto consecutivo en su trayecto al rio Vilcanota, por ello y para que a futuro no exista daño sobre el recurso natural, se tomó la iniciativa de modificarla, involucrando a 8 nuevas Comunidades Campesinas ubicadas entre los 3600 a 4000 metros sobre el nivel del mar pertenecientes a los distritos de Túpac Amaru (Pampahuasi, Toccoccori, Ccochapata, y Ccotaña) y Yanaoca. (Pongoña, K'ascani, Chignayhua y Hanccoyo).

\section{La llegada del proyecto}

Con la nueva empresa encargada de realizar la construcción del Gasoducto sur peruano, se empezó a efectuar el vínculo y contacto inicial con las diferentes Comunidades Campesinas. El primer encuentro fue en el año 2015, solicitando el permiso correspondiente a las autoridades comunales para poder explicar el proyecto y presentarse ante la población, los encargados de realizar estas tareas eran los relacionistas comunitarios. En un principio los pobladores se sentían ansiosos con la llegada del proyecto, porque escucharon que traería beneficios y trabajo. Había comentarios de los demás sectores que era similar a la empresa "kuntur" que brindaba obsequios.

El proyecto brindaba una serie de factores positivos y negativos, primando el último, que hacía alusión a las modificaciones dentro de sus entornos naturales y sociales, ocasionando desequilibrio e inestabilidad por la inclusión de factores externos nuevos. El choque de intereses de los actores sociales que responden a diferentes identidades y contextualidades espacio-temporales, del mismo modo a diferentes dinámicas de relaciones sociales, posibilita diversas vías de acción (Debuyst, 1961). En este sentido, la conexión e interacción entre ambas partes es un proceso clave para redefinir relaciones internas de sí mismas y de ellas entre sí, que satisfaga intereses. El temor e incertidumbre del impacto negativo sobre lagos, ríos y terrenos agrícolas que son elementos básicos y primordiales para la producción de sus alimentos, constituyen un riesgo para la salud y la vida de las personas que habitan las zonas de proyectos extractivos, contexto en el cual, se presentan conflictos entre el beneficio económico (extractivo) y los intereses sociales (Muñoz- Duque, Pérez y Betancur, 2020). En este sentido, las actividades que realice la empresa deben estar evidenciadas de forma transparente, justa y en beneficio de la población, dejando de lado acciones de engaño y mentira.

El ambiente se considera espacio de vida y sobrevivencia ecológica, económica y sociocultural, es desplegado en prácticas y formas de expresión heterogéneas como parte de un contexto político, económico, sociocultural local y global. La investigación concuerda con la noción del autor, al contemplar que los espacios naturales y culturales son primordiales para el desarrollo de los seres humanos, evidenciado en el respeto, cuidado y armonía que defienden los pobladores de la provincia de Canas (Paz, 2014).

Las relaciones comunicativas en los proyectos de impacto ambiental son esenciales, cada sector tiene distintos intereses y motivaciones que pueden ser contrapuestos por inadecuadas acciones comunicacionales. Esto, puede tener un carácter especulativo de la información debido a la falta de especialización (Rodríguez, 2011). Por lo tanto, la 
comunicación es una lucha expresa entre al menos dos partes interdependientes que perciben que sus objetivos son incompatibles, sus compensaciones son reducidas y la otra parte les impide alcanzar los mismos (Borisoff, 1991). Asimismo, las propuestas contrarias a sus intereses, originan el estancamiento de una de las partes, presentándose incompatibilidades respecto a la expectativa de acceso a capitales económicos, sociales, culturales y simbólicos que permiten suplir sus necesidades y motivaciones (Cuesta, 2011). En este contexto, se concuerda que las relaciones entre empresa y comunidades estudiadas se fueron debilitando por una serie de mecanismo de involucramiento desfavorables, evidenciado en la falta de dialogo, escasa información y compromiso. Un aspecto a destacar fue la falta de dominio del idioma local (quechua), fundamental para una comunicación fluida, adecuada y entendible. Provocando inseguridad en la población al no saber con certeza qué actividades realizará la empresa. Del mismo modo, la convivencia en el entorno no generó lazos de confianza, por el contrario, fueron visualizados como visitantes o foráneos que solo aparecían para solicitar algún requerimiento de manera esporádica.

Tabla 1.

Perspectivas iniciales sobre el proyecto Gasoducto Sur Peruano Comunidades Campesinas del distrito de Túpac Amaru.

\begin{tabular}{lll|l}
\hline & Positiva & Negativa & Total \% \\
\hline PAMPAHUASI & $80 \%$ & $20 \%$ & 100 \\
TOCCOCCORI & $50 \%$ & $50 \%$ & 100 \\
CCOCHAPATA & $10 \%$ & $90 \%$ & 100 \\
CCOTAÑA & $30 \%$ & $70 \%$ & 100 \\
\hline
\end{tabular}

Tabla 2.

Perspectivas iniciales sobre el proyecto Gasoducto Sur Peruano Comunidades Campesinas del distrito de Yanaoca.

\begin{tabular}{lll|l}
\hline & Positiva & Negativa & Total \% \\
\hline PONGOÑA & $30 \%$ & $70 \%$ & 100 \\
K'ASCANI & $40 \%$ & $60 \%$ & 100 \\
CHIGNAYHUA & $40 \%$ & $60 \%$ & 100 \\
HANCCOYO & $70 \%$ & $30 \%$ & 100 \\
\hline
\end{tabular}

Las tablas 1 y 2 , muestran las posturas de los pobladores, la comunidad que tiene una posición positiva respecto a los inicios del proyecto es Pampahuasi con $80 \%$ y $70 \%$ Pongoña y Hanccoyo, por el contrario, Ccochapata, Ccotaña, $\mathrm{K}^{\prime}$ ascani y Chignayhua, tienen un punto de vista relativamente negativo siendo la más considerable Ccochapata en $90 \%$. Así también Toccoccori se encuentra aún indecisa con $50 \%$. Por lo tanto, el contacto inicial no era de negación absoluta, por el contrario, según los datos la mayoría de los sectores tenía perspectivas dubitativas que podía modificarse.

\section{Perspectiva negativa}

Las poblaciones tienen como noción que su medio de vida y entorno es sagrado, cualquier persona no puede ni debe entrar en su territorio sin la debida autorización. Estas circunstancias fueron debilitando los lazos que se estaban entablando entre la empresa Odebrecht y las Comunidades. La sociedad percibe, define y evalúa que determinado contexto ambiental amenazante con las condiciones de reproducción alcanza una respuesta social públicamente constituida, encaminada a su remediación o neutralización (Lezama, 2004). Cada localidad está dirigida y regida por una serie de reglas y principios entre los cuales prima el respeto a su entorno y la protección del mismo, no conciben la idea de modificar lazos de convivencia ni permitir que entes externos amenacen su entorno.

Los conflictos que surgen en el micro nivel, entre múltiples subsistemas que componen una sociedad, como grupos, familias, clanes, villas, instituciones, etc., al ser resueltos de acuerdo con las valorizaciones, costumbres y leyes de la sociedad, permiten que ésta reacomode periódicamente y en distintos niveles, esto es, que la armonía y equilibrio social dependen de una posición balanceada en las instituciones y el comportamiento social (Gluckman, 1955). Las modificaciones en su entorno social y cultural son evidentes, los pobladores de las Comunidades Campesinas se encuentran pensativos, preocupados $\mathrm{y}$ temerosos por lo que pueda suceder, sienten que el hecho de permitir que máquinas y otros elementos tecnológicos entre en contacto con su medio ocasionara el castigo de los entes sagrados que ellos veneran y respetan. Un marco legitimador de la violencia se concreta en actitudes, esta forma hace referencia a aspectos de la cultura que la legitiman a través del arte, religión, filosofía, derecho, etc. (Galtung, 1989).

La violencia cultural y estructural son menos visibles, pues en ellas intervienen más factores, en vista que, detectar su origen, prevención y remedio es más complicado. Referir las formas de la violencia en espacios locales y regionales es importante a fin de vislumbrar sus lógicas, 
sentidos y significaciones particulares (Mejía, 2017). Al respecto, la cosmovisión andina es variada y diferencial, la investigación muestra el caso, por ejemplo, de la Pachamama o madre tierra, contemplada como pilar fundamental de subsistencia y alimento, encargada de proporcionar los productos y medios para vivir. Los actores sociales involucrados en un conflicto apoyan sus demostraciones basados en evidencia práctica que consideran un esclarecimiento verdadero y objetivo de la realidad (Zamora, 2017). Según su interpretación de los comuneros los Apus (cerros) tutelares que se ubican alrededor de su espacio poseen vida y los protegen, el contacto o destrucción ocasionaría castigo y perdición. Es complejo entender un espacio cultural que es clave para internalizar formas de vida y pensamiento distinto. En este sentido, cada aspecto erróneo fue acrecentado aún más la negativa al proyecto.

\section{Causas de los conflictos socioambientales entre las Comunidades Campesinas de Canas y el Proyecto Gasoducto Sur Peruano}

Los problemas socioambientales tienen diferentes connotaciones y motivaciones orientadas en intereses contrapuestos. Se pudo evidenciar la existencia de una serie de motivos y beneficios opuestos que resquebrajaron los vínculos de dialogo hasta concluir en la negativa del proyecto:

\section{Información errada en los talleres (MEIA)}

El primer punto estuvo relacionado con los trabajos $\mathrm{y}$ talleres informativos, que fueron tergiversados y poco objetivos. Mostrando datos erróneos de cada sector en relación a: población, flora, fauna, hídricos, aspectos sociodemográficos, económicos y salud. Conllevando al descontento y rechazo popular.

Tabla 3.

Opiniones y dudas más sobresalientes dentro de los talleres (MEIA).

\begin{tabular}{lc}
\hline & $\%$ \\
\hline POSIBILIDAD DE REALIZAR OBRAS DENTRO & $5 \%$ \\
DE CADA COMUNIDAD (COLEGIOS, POSTAS & \\
DE SALUD, ETC.) & \\
\hline $\begin{array}{l}\text { RETRIBUCIÓN ECONÓMICA POR EL USO DE } \\
\text { TERRENOS COMUNALES }\end{array}$ & $5 \%$ \\
\hline CONTAMINACIÓN AMBIENTAL & $65 \%$ \\
\hline CONTRATACIÓN DE MANO DE OBRA LOCAL & $10 \%$ \\
\hline AREAS COMUNALES QUE RECORRE LA & $15 \%$ \\
TRAZA DEL PROYECTO & \\
\hline TOTAL & $100 \%$ \\
\hline
\end{tabular}

En relación a la tabla 3. los pobladores muestran que la perspectiva de mayor preponderancia es la "contaminación ambiental". Consideran que la tubería de gas podría colapsar y reventar en algún momento, ocasionando la desertificación de los suelos productivos, así mismo especulan que dichos tubos servirían para llevar sus reservas de agua a otros sectores (ojos de agua, manantiales, lagunas y ríos). El estudio corrobora que las empresas privadas al introducirse en un determinado lugar para obtener ingresos realizan sus actividades sin tener una mirada social y humana solo piensan en obtener lucro y ganancia dejando de lado las características sociales, culturales y económicas que posee cada lugar (Harvey, 2004). De esta forma, la percepción negativa a esta empresa se debe a los impactos y riesgos socioambientales irreversibles asociados a la explotación de sus recursos naturales, así también las posibles consecuencias sociales que provoca sus actividades en los pobladores locales, sin lograr un notable y permanente crecimiento económico en las zonas afectadas, los cuales poseen diferentes representaciones y funciones dentro de su contexto.

El sistema social nace con unos objetivos claros, absolutamente pragmáticos o utilitarios, concretados, de ahí el hombre se: adapta al entorno, logra sus metas, conserva pautas de operación interna para mantenerse integrado (Lorenzo, 2001). En efecto, dentro del contexto comunal consideran que cada elemento cumple una tarea, todo está estructurado funcionalmente. Existe una relación hombre- naturaleza compleja de separar.

Las empresas privadas despojan a las comunidades de su mundo ecológico, económico, territorial y cultural dirigidos por el control transnacional (Harvey, 2004). Asimismo, la empresa en su afán de lograr sus propósitos no examina barreras ni consecuencias, por el contrario, existe un abandono del Estado y entrega de sus territorios a las empresas como una estrategia de privatización (Bolados, 2016). El estudio guarda coherencia con los autores, revelando que las empresas hacen pagos irrisorios a las comunidades por el uso y paso por sus terrenos agrícolas, subsanar perdidas, modos de vida y dominio territorial y económico (ganancias), trabajo subordinado y discriminatorio (obreros y peones jóvenes) y sobornos a autoridades y líderes comunales para la aceptación del proyecto. Estas circunstancias 
provocaron la ruptura de relaciones comunicativas y por consiguiente la negativa al proyecto.

Tabla 4.

Causas finales para la negativa del proyecto.

\begin{tabular}{ll}
\hline & $\mathbf{\%}$ \\
\hline $\begin{array}{l}\text { Información errada e insuficiente en los talleres } \\
\text { (MEIA) }\end{array}$ & $30 \%$ \\
\hline Contratación de mano de obra local & $5 \%$ \\
\hline Sobornos para la aceptación del proyecto & $10 \%$ \\
\hline Pagos mínimos por el uso de sus terrenos & $10 \%$ \\
\hline $\begin{array}{l}\text { Irrumpir en las Comunidades sin la debida } \\
\text { autorización }\end{array}$ & $15 \%$ \\
\hline $\begin{array}{l}\text { Posibles consecuencias negativas que ocasionaría el } \\
\text { proyecto (impactos ambientales, sociales, económicos }\end{array}$ & $30 \%$ \\
y culturales) & $100 \%$ \\
\hline TOTAL &
\end{tabular}

En relación a la tabla 4 . Se puede evidenciar que las causas más preponderantes se encuentran relacionadas a las consecuencias negativas que provocaría el proyecto con un $30 \%$, de igual manera la escasa y errónea información en los talleres MEIA 30\%, y finalmente aspectos como permisos comunales $15 \%$, pagos por el uso y paso de terrenos $10 \%$, sobornos $10 \%$ y contratación de mano de obra local 5\%. En términos generales, las causas de los conflictos evocan la idea que las Comunidades Campesinas son actores sociales invisibles considerándolos los pobres del campo, los provincianos de la sierra, cuyos andes están llenos de ricos recursos naturales que pueden acabar siendo drenados hacia la capital del país o las metrópolis mundiales, sin dar oportunidad a los desarrollos regionales y locales. El modelo 2 de desarrollo actual global atribuye una serie de esquemas que ponen en riesgo la supervivencia misma de la especie humana (La Rotta y Torres, 2017), dejando a la vez las huellas ambientales imborrables de este tipo de proyectos.

\section{Participación del Estado y la empresa privada en la solución de conflictos socioambientales en el Proyecto Gasoducto Sur Peruano}

La participación del Estado peruano en cada etapa y proceso de involucramiento que efectuaba la empresa pasó desapercibido, invisible y sumiso. Pese a tener un rol preponderante en los conflictos socioambientales, es el espacio más importante donde desarrollar el debate a nivel ideológico y que influye mayormente en el nivel formativo y operacional; además, es un actor político en los procesos de ajuste estructural $\mathrm{y}$, la posición que asuma en los conflictos dependerá de los niveles de presión e influencia que los actores nacionales e internacionales tengan sobre él (Homer,1999). Fue evidente la coalición con la empresa dejando pasar por alto muchas acciones negativas, permitiendo divulgar información errada y contraria para la población.

El Estado es el empleador de la violencia y constructor de la legalidad (Seoane, 2012). Es indudable que todo proceso económico siempre tenga tamices ocultos, pues, es un poder de clase que se sostiene en flexibilizar las leyes para que las distintas designaciones del capital se apropien de los recursos productivos $y$ financieros de sus territorios, siendo las relaciones de poder constitutivas de los vínculos sociales, por lo cual resultan inevitables (Wertheimer, 2019). La economía política del capitalismo moderno ha transformado y está transformando los espacios que podríamos denominar locales (Mc Phee, 2010). El Estado quiso permitir el pillaje y astucia de la empresa sobre los bienes ambientales y culturales que cada sector posee, contemplando que "desarrollo" según su enfoque es la transformación, extracción y destrucción de espacios naturales. Así también, de formas de vida instauradas históricamente por la creatividad intelectual de cada poblador.

De esta forma está en juego las experiencias cotidianas de las Comunidades Campesinas, y empresas y Estado, significa orden y racionalidad para prosperar en las dimensiones económica, productiva, política, social y cultural (Fontaine, 2003).

\section{Conclusiones}

La perspectiva de las Comunidades Campesinas de Canas respecto al Proyecto Gasoducto Sur Peruano sufrió modificaciones con el tiempo. En un inicio las Comunidades estaban ansiosas por conocer que beneficios traería el nuevo proyecto, con el transcurrir de los días y las acciones que realizaba la empresa fue modificando su posición a una imagen negativa. Desde un inicio no informaron de forma adecuada y en su idioma nativo (quechua) las acciones que generaron la falta de comprensión sobre las actividades del proyecto; también la poca participación, relacionamiento e involucramiento con las Comunidades Campesinas ocasionaron que el proyecto sea mal visto; ingresar hacia su entorno natural, social y cultural sin permiso quebró las relaciones sociales. Por otro lado, la perspectiva de la empresa Odebrecht está representado por 
disímiles problemas ocurridas con las diferentes Comunidades Campesinas de Canas debido a ciertas posiciones asistencialistas, intereses particulares y políticos de algunos miembros de la población, los cuales tergiversaron el propósito y desarrollo de las actividades de la empresa. Por otro lado, proponen una serie de programas sociales, los cuales tienen la intención de mejorar la situación económica y social de las poblaciones involucradas en la construcción del proyecto.

Las causas de las Conflictos Socioambientales entre las Comunidades Campesinas de Canas y el Proyecto Gasoducto Sur Peruano son diversas, preponderando la escasa información de la empresa respecto al accionar del proyecto dentro de los talleres informativos (MEIA), así también la desconfianza existente por factores desequilibrantes como sobornos, el pago por el uso de sus terrenos y la negativa de la empresa a realizar obras en sus Comunidades. En el mismo sentido, brindar información falsa sobre sus localidades pese a permitir que se hagan las investigaciones correspondientes y la comunicación asimétrica entre el proyecto y las poblaciones. Igualmente, por las posibles consecuencias que ocasionaría la construcción, predominando la contaminación ambiental, el desequilibrio ecológico y la modificación de factores culturales de su entorno.

La participación del Estado y la empresa privada en la solución de los conflictos socioambientales en el Proyecto Gasoducto Sur Peruano es imperceptible porque su intervención dentro de las acciones del proyecto fue limitada colaborando y teniendo como actividades únicas los talleres y audiencias medio ambientales. En ese sentido, la empresa no pudo solucionar los conflictos de forma individual, necesitó el apoyo del Estado Peruano que no se hizo presente. Por otro lado, los proyectos sociales que desarrolla en la zona como Beca 18, Programa Juntos y Pensión 65, no benefician a toda la población siendo algunos los privilegiados. También, dentro del proyecto Gasoducto Sur Peruano se contempla a un Estado muy permisivo y flexible que consiente arbitrariedades y engaños de la empresa con la finalidad de lograr beneficios particulares.

\section{Referencias bibliográficas}

Aranda, J. (2004). Principales desarrollos de la sociología ambiental. Ciencia Ergo Sum, 11(2), pp. 199-208.
Basombrío, C., Rospigliosi, F., y Valdés, R. (2016). "Conflictos sociales en el Perú 20082015. Un análisis a profundidad a partir de la evidencia empírica". Perú: Capital Humano y Social S.A.

Bolados, P. (2016). "Conflictos socio-ambientales/ territoriales y el surgimiento de identidades post neoliberales", Izquierdas, 31, pp. 102129.

Borisoff, D. (1991). "Gestión de conflictos: un enfoque de las técnicas de comunicación". España: Ediciones Díaz de Santos.

Castro, J. (2013). "Sociología para analizar la sociedad”. Lima. Editorial San Marcos.

Cuesta, O. (2011). "La Comunicación en la transformación de los conflictos". España: departamento publicaciones Universidad Santo Tomas.

DE Echave, J., Diez, A., Huber, L., Revesz, B., Lanata, R. y Tanaka, M. (2009). "Minería y conflicto social”. Lima: CBC, CIPCA, CIES y IEP.

Debuyst, F. (1961). “La Población en América Latina”. Oficina Internacional de Investigaciones Sociales de FERES, Centro de Investigaciones Socio-Religiosas.

Debuyst, F. (1999). "Actores, coherencias acciónales y lógicas sociales". Universidad de Chile.

Defensoría del Pueblo (2005). "Informe Extraordinario. Los conflictos socioambientales por actividades extractivas en el Perú". Lima: Defensoría del Pueblo. Fecha de consulta: 20 de setiembre 2017 (https://www.defensoria.gob.pe/modules/ Downloads/informes/extraordinarios/inf extraordinario 04 07.pdf.)

Entelman, R. (2005). "Teoría de conflictos". Barcelona - España: Gedisa.

Fontaine, G. (2003). "Enfoques conceptuales y metodológicos para una sociología de los Conflictos ambientales". Pagina Library. Visita el 5 de enero de 2017 (<http://library. fes.de/pdf- files/bueros/kolumbien/01993/12. $\mathrm{pdf}>$.)

Galtung, J. (1989). “Violencia cultural”. Gernika Gorgoratuz. España.

Gavaldá, M. (2005). "Los conflictos ambientales del gas boliviano". Iconos. Revista de Ciencias Sociales, 21, pp. 57-66.

Gluckman, M. (1955). "Costumbre y conflicto en áfrica”. Oxford Blackwell. 
Harvey, D. (2004). "El Nuevo Imperialismo: Acumulación por desposesión. Socialist Register". Buenos Aires: CLACSO.

Homer, T. (1999). "Environment, scarcity, and violence". Princetown University Press.

La Rotta, A. y Torres, M. (2017). "Explotación minera y sus impactos ambientales y en salud. El caso de Potosí en Bogotá". Saúde Debate - Rio de Janeiro, 41(112), pp. 77-91. DOI: 10.1590/0103-1104201711207.

Lezama, J. (2004). "La construcción social y política del medio ambiente”. México: El Colegio de México.

Mc Phee, B. (2010). "Conflictos ambientales y respuestas sociales: el caso de reetnificación de la comunidad de Quillagua", Rev Mad, 22: 42-55.

Mejía, E. (2017). "Sociedad civil y violencia: el conflicto por el parque eólico en territorio ikojt de San Dionisio del Mar". Acta sociológica, 74, pp. 81-106.

Merlinsky, G. (2017). "Cartografías del conflicto ambiental en argentina: Notas teóricas metodológicas". Acta sociológica, 73, pp. 221-246.

Muñoz-Duque, L., Pérez M. y Betancur, A. (2020). "Despojo, conflictos socioambientales y violación de derechos humanos. Implicaciones de la gran minería en América Latina". Rev. U.D.C.A Act. \& Div. Cient. 23(1), pp. 1-10. DOI: 10.31910/rudca.v23.n1.2020.988

Orellana, R. (1999). "Aproximaciones a un marco teórico para la comprensión y el manejo de Conflictos socioambientales". Quito Ecuador: Ediciones ABYA- YALA.

Ortiz, P. (1999). "Comunidades y conflictos socioambientales. Experiencias y desafios en América Latina". Quito - Ecuador: Ediciones ABYA-YALA.
Ortiz, P. (2004). "Curso de capacitación en metodologías de tratamiento de conflictos socio ambientales". Quito - Ecuador: Fundación Futuro Latinoamericano.

Pardo, G. y Cedeño, M. (1997). "Investigación en salud". Colombia: McGraw Hill Interamericana.

Paredes, O. (1996). “Amazonia 500 años”. Cusco: Fondo editorial Universidad Nacional San Antonio Abad del Cusco.

Paz, M. (2014). "Conflictos, conflictividades y movilizaciones socioambientales en México: Problemas comunes, lecturas diversas". Cuernavaca: CRIM, UNAM, Miguel Ángel Porrúa, Eds.

Rodríguez, L. (2011). "Los paradigmas de la comunicación en el Altiplano". Comuni@, cción: Revista de Investigación en Comunicación y Desarrollo, 2(1), pp. 33-38.

Roos, M. (1995). "La cultura del conflicto". España: Editorial Paidós.

Seoane, J. (2012). "Neoliberalismo y ofensiva extractivista. Actualidad de la acumulación por despojo, desafíos de Nuestra América". Theomai 26, segundo semestre.

Valderrama, S. (2019). "Pasos para elaborar proyectos de investigación cientifica”. Lima. Perú: Editorial San Marcos.

Wertheimer, M. (2019). "Una lectura de los conflictos en torno al uso del espacio costero en Vicente López a partir de las nuevas sociologías pragmático-pragmatistas". Cuadernos de Geografia: Revista Colombiana de Geografía, 28, pp. 408-422. DOI: $10.15446 /$ rcdg.v28n2.73458.

Zamora, I. (2017). Constructivismo y realismo crítico en los conflictos ambientales. Acta sociológica, 73, pp. 273-294. 